\title{
Motivation and Pedagogical Relationship: A Case Study in Rabo de Peixe, Azores, Portugal
}

\author{
Sandra Patrícia Pereira, Tereza Ventura \\ University Fernando Pessoa, Azores - Portugal
}

\begin{abstract}
The action-research project that supports the present communication aims, through a Motivation Program implementation, to contribute to the understanding of the effect of motivation in students with a school record of failure background, integrated in classes with alternative school programs, its relevance to improve school results and the importance of the pedagogical relationship in the motivation for learning. It focused on 71 individuals in a total of 154, from Rabo de Peixe Azores, 53.5\% males and 46.5\% females, between the ages of 10 and 17, with an age average of 11.6. 43 of these students benefited from a mentoring program. It was shown that students integrated in Education Recovery Programs show motivation levels and school results below the average. It was also proven that the Motivation Program significantly improved the motivation and the academic performance and unequivocally minimized social, family, financial and cultural inequalities. The students considered as decisive for motivation and for success the investment in self-efficacy beliefs, the development of self-concept, the promotion of education through affection and the quality of the pedagogical relationship.
\end{abstract}

\section{Introduction}

This research started due to the fact that there were a high number of problematic students in the alternative program classes at Rui Galvão de Carvalho School - Azores and aimed to answer the initial questions: Can motivation have a positive effect on the learning process of these students? How can we increase such motivation?

The study was based on the analysis of 71 individuals in a total of 154, from Rabo de Peixe Azores, $53.5 \%$ males and $46.5 \%$ females, between the ages of 10 and 17, with an age average of 11.6. 43 students (61\%) benefited from a mentoring program.

The sample was submitted to a Motivation Program (MP), based on the Constructivist and Interactionist perspectives of learning, integrating the principles of social constructivism of Vygotsky and Bruner and the ecological vision of Brufenbrenner. We assumed that the student is able to build his/her own knowledge in a critical and reflective dynamic, supported by the knowledge that he/she has of the world [1]. He/she must do so partnering with a teacher who will facilitate and mediate the discovery and the appropriation of knowledge, promoter of participation, of involvement and cooperation, with a regular recourse to the experimental teaching, to research and to problem solving [2]. The pedagogical relation is perceived as the foundation for all cognitive and personal development in the context of the classroom. The affective and cognitive aspects are equally appreciated, assuming that affectivity, more than the driving force of learning, is the capital factor that defines it and that will serve as the motor of the whole cognitive process, favoring the class dynamics, by sharing and by cooperative learning, developing the participants' resilience, as well as their self-improvement skills. An affectionate pedagogical relationship is, therefore, the basic and fundamental tool for the quality of the teachinglearning process, capable of enhancing the student, giving credibility to his/her opinions and appreciating his/her interventions. It is assumed in this article that learning through affections, although it does not have the capacity per se to modify the structures of the cognitive system and intelligence, allows to boost or inhibit the full exercise of his/her potentials, avoiding affective and cognitive constraints and blockages, from which depends the optimization of the individual resources [3].

We assumed learning as a personal construction, based on a change more or less permanent, which occurs on the behavior as a result of practice and of life experience, as a result of interaction between the subject, his/her behaviors, his/her life context and the way the teaching activity is organized, in an invisible construction which includes practice and execution [4].

With regards to the motivation theories, this study favored the Self-Determination of Macrotheory of Deci and Ryan, which cares about the development and function of the personality in social contexts and about the causes and consequences of the self-determined behavior [5], with an articulated approach of complementarity and continuum between extrinsic and intrinsic motivation, advocating equity in the role that both have in the promotion of learning [6] e [7]. It is believed that the intrinsic motivation can occur not only by itself, but also as a result of extrinsically motivated behaviors that, after internalized, are recognized as selfregulated [5] e [8].

As a motivational predictive factor, the influence of the integration of students in repeated school failure mentoring programs was analyzed. It is believed that the emotional proximity, integrated in a school tutoring program, plays an important role in 
the processes of cultural transmission and internalization of values, and presents itself as a crucial factor in the educational contexts. The understanding of motivation as a mediated process by cognitive and affective variables is, according to Paiva and Boruchovitch [9], a major breakthrough in the field of education, with an emphasis on the quality of the pedagogical relationship and the role that the teacher and tutor can play in mobilizing students in their implication in the learning process. It is recognized that tutoring can be assumed as an important protective factor for young people with difficulties in behavioral or learning levels.

In summary, a Motivation Program was defined, applied and tried. Through the quality of the pedagogical relationship, the teaching through affections, the strengthening of self-concept and selfefficacy beliefs, emphasizing the significance of learning, in a suitable molding attribution of causality and in a perspective of involvement and participation, was able to influence the improvement of learning, school results and, hence, the recovery of students in school failure.

\section{Study Description}

As explained above the implementation of the Motivation Program which aimed to establish a positive and reciprocal correlation between the quality of the pedagogical relationship and the increase of the motivational levels of the target population, presenting them as factors of the promotional learning and inhibitors of the social, family, financial and cultural inequalities, enhancing the access to success of students with a record of repeated failure background.

On a first phase, we applied the Motivation Scale for Learning - EMAPRE A (minimum score of 28 negative points and a maximum of 28 positive points, considering the student motivation from 0 points) with the objective of assessing the target population motivation levels at the beginning of the study. It was also applied the Portuguese Knowledge Test (Pre-test) in order to assess the students' knowledge of the Portuguese at this moment. Then, the Motivation Program was implemented and applied during nine months. Halfway through the implementation of the program a questionnaire was introduced to help to characterize the students, as well as to understand their perspectives of the issues related to their motivation and its importance in learning, as well as to assess the importance given by them to the quality of the pedagogical relationship, in the increase of the motivation and the success in learning. On the second phase, a data collection, with the EMAPRE B, was applied with the objective of assessing the motivation levels of the same students at the end of the study. The Portuguese Knowledge Test (Post-test) was also applied to assess the
Portuguese knowledge generated by the same students at the end of the study. The goal was to establish a comparison of the results in terms of distribution, frequency and correlation capable to affirm or deny the hypotheses and sub-hypotheses presented, testing the influence of the motivation and the pedagogical relationship in learning and improving the students' performance.

Bearing in mind that the EMAPRE was used to assess the Brazilian population, before the first application a pre-test application was held by fifteen students with the same age, the same school, the same year and with similar difficulties diagnosed within the target population. It was found that it would be beneficial to change some words used in the EMAPRE as it distances from the standard Portuguese, the changes were undertaken, and all the data collection instruments were submitted to previous analysis and validation of experts in the field. The internal consistency of the organizational environment and the participation in the questionnaire was assessed by using Cronbach's Alpha coefficient of internal consistency. For the data collection regarding the qualitative method, it was used the teacher's record grids, the students' files, the "Projeto Curricular" (Curricular Project) of the different classes involved, the Moodle MotivArte course and some classroom records that allowed to enrich each student's profile.

\subsection{Methodology}

Bearing in mind the problem studied, the established objectives and the defined starting question, methods from different traditions were used, in a perspective of inter-methods triangulation. It started with the quantitative method through the identification of hypotheses, supported by all the literature read and experience, and its predefined instruments of data collection, with the objective of demonstrating tendencies in terms of distribution, frequency and correlation. It was added a qualitative method in order to value the researcher's interaction with the field and the importance of his/her subjective interpretation as an explicit part of the production of knowledge. It was intended to follow a path able to promote the articulation of results, the contextual delimitation and the survey of new leads for future research, combined with a need for more accurate communication, with a structure defined a priori, able to incorporate and control the statistically admissible error.

In short, using the quantitative approach, it is intended to contribute to the understanding of the initial question, supported by a greater rigor and objectivity, since, even though it is not possible to extrapolate to the general population, one can conclude and infer in the studied case tendencies for similarly broader contexts. With the qualitative 
approach, it is intended to contextualize the field of work and take into account the specific characteristics of the participants in the process, in order to facilitate a better understanding of the obtained results. It is assumed that they can never be exclusively attributed to motivation, since the available case study and the immensity and specificity of variables make it difficult to establish a control group where absolute equality is safeguarded against the characteristics of the experimental group.

As such, it becomes essential to include complementary questions that allow the understanding of the results from a triangular perspective, inferring about new hypotheses, supporting or rejecting theories, finding points of divergence or convergence that get in conflict with the search for new contributions to our problem.

The triangulation sought in this article also refers to previous studies in the study areas, trying to compare, validate, contrast and increase the field of vision of different perspectives and approaches.

With regards to the quantitative method, it was the aim of this study: to contribute to the understanding of the effect of motivation in students with repeated school failure and its importance to improve school performance. It was a specific goal: to verify if the students with repeated school failure were being motivated to improve their school performance.

The following general hypotheses were outlined: G.H.1. Students integrated in recovery school programs show more motivation and a higher success in learning.

G.H.2. A more affective pedagogical relationship, considered by the students integrated in the school recovery programs, is associated with the increase of motivation for learning.

The following sub-hypotheses were defined: G.H.1.1. Students in school recovery programs are poorly motivated for learning.

G.H.1.2. The older is the student in the recovery groups, the lower is the degree of motivation.

G.H.1.3. Male students integrated in education recovery programs are less motivated than the female.

G.H.1.4. The introduction of a motivation program has significantly raised the motivational levels of students integrated in the school recovery programs. G.H.1.5. The increase of motivation raised significantly the performance of students in the school recovery programs.

G.H.2.1. The pedagogical relationship influences the motivation of students in the school recovery programs.

G.H.2.2. An affective pedagogical relationship positively influences the educational achievement of students integrated in the education recovery programs.
With regards to the qualitative perspective, the aim of the study was: to contribute to the understanding of the importance of the pedagogical relation in the learning motivation of the POI students. The goal was: to verify if, in a pedagogical relation considered more affectionate by the POI students, they feel more motivated for learning.

Because of this, the following questions have been established:

Question 1: What other factors, according to the students integrated into school recovery programs, influence learning?

Question 2: What other factors, according to the students integrated in school recovery programs, are important for motivation?

Question 3: What are the factors that the students integrated in education recovery programs consider most important for the improvement, throughout the school year, in their school results in the Portuguese subject?

Question 4: What are the activities most appreciated by the students during the Motivation Program?

\subsection{Contextual characterization}

The study was conducted at Rui Galvão de Carvalho School, in Rabo de Peixe, Azores.

The Azorean archipelago has nine islands and a total of 246.102 residents, living $56 \%$ on the island of São Miguel. There is an increase of approximately $2 \%$ of the Azorean population and $4.5 \%$ of the population of São Miguel [10]

Rabo de Peixe is internationally known as socioeconomically disadvantage, highlighted in the Census of 2011 [10], as the most populated town in the archipelago, with about 178 inhabitants per square meter. It is also the youngest town, where $33.8 \%$ are less than 18 years of age, with an age rate opposite to the national reality, since the elderly population represents only $5 \%$ of the residents. The population growth increased by $24 \%$ in the number of households, with an average household of 4.6 people, as opposed to the 2.6 national standard. It is stated that $34.6 \%$ of the population of the town is illiterate; $28 \%$ only attended primary school; $4.8 \%$ completed secondary school and only $3.6 \%$ completed university.

The low qualifications have an impact on the employability, being the unemployment rate the highest in the country [10]. Rabo de Peixe is thus the Azorean town with more financial benefits and protection against social exclusion, being the target of several European initiatives, especially the European Free Trade Association, whose investments, between 2005 and 2008, were around the twenty-three million euros.

In conclusion, the town of Rabo de Peixe stands out for its high population density, for the significant increase in its population and its families, as well as 
for their size (about 35\% with five or more elements), for low academic and professional qualifications, for the employment precariousness and for the high unemployment rate, as well as for the number of beneficiaries of support and protection against social exclusion.

\subsection{Characterization of the school}

Rabo de Peixe School is located in the town of Rabo de Peixe and the school population is a combination of students from the surrounding villages of Pico da Pedra, Calhetas and Rabo de Peixe. Since there is a high number of children and youth at risk in the community, this geographic area constitutes a Territory of Educational and Social Intervention with priority in the field of Education, benefiting from the efforts of various institutions and bodies.

The School Unit consists of Rui Galvão de Carvalho School, where there are students from the $5^{\text {th }}$ until the $9^{\text {th }}$ grades (normal curriculum), students attending Opportunity Program I, II and III, Vocational Opportunity Program, Alternative Curricular Project, Differentiated and Transition to Active Life Curricular Project, counting also with five primary schools with preschool.

It is emphasized the fact that in Rui Galvão de Carvalho's School, in the year under study, there were twenty-eight classes of normal curriculum and twenty-seven classes covered by an education recovery program, evidence of the difficulties and the particular reality of this community.

Referring more specifically to Rui Galvão de Carvalho's School, as it was in this building that the activities under study were developed, it is important to add that the physical structure of the building is not up to date, has very limited space for the student's population (1106 students). With respect to the school results, it is essential to mention that Rui Galvão de Carvalho School presents an extremely worrying deficit compared to the national average, and, in 2015, in the Final Portuguese Exams, it was classified second-to-last in the National Schools Ranking.

\subsection{Characterization of the target population}

The studied population consisted of 71 individuals integrated in the alternative educational program classes $(53.5 \%$ boys and $46.5 \%$ girls) with an average age, at the beginning of the study, of 11.6 years of age. 43 students $(61 \%)$ benefited from a mentoring program.

Before the enrolment in these classes, $92.6 \%$ of the students had failed two school years and $7.4 \%$ had failed more than twice. $38 \%$ had already enrolled in the Special Education System.

A brief analysis of the students' family profile allows it to see the low level of qualifications among parents: $21.1 \%$ of the fathers and $11.3 \%$ of the mothers can't read or write and $34.5 \%$ are illiterate. There is a greater attendance in primary school grades 1 to 4 (fathers: $75 \%$, mothers: $72 \%$ ), with only $1 \%$ of the mothers having attended the 7 th and 9th grades. The low qualifications reflect the high unemployment rate (fathers: 30\%, mothers: 92\%) and the consequent financial instability. There is a high household rate (5.7 persons), as well a significant number of children per couple (4 children: $28 \%, 3$ children: $24 \%, 5$ children: $16 \%, 6$ children: $8 \%, 9$ children: $6 \%$ ). $63 \%$ of the families benefit from Social Assistance, and all students receive support from the Student Assistance School Program, being $78.9 \%$ of the studied families covered by the highest school financial aid. $73 \%$ of these households rely on the State protection to ensure housing. $21.1 \%$ of the students are being supervised by the Children Protective Services, being $8.5 \%$ monitored by the Juvenile Court. $7 \%$ of the students were institutionalized, being $1.4 \%$ still under State Guardianship. It is shown, therefore, that $36.6 \%$ of the studied population is or was in a vulnerable emotional and / or familiar situation.

\section{Tutoring in school context}

The existence of tutoring in a school context is a growing reality and is recognized as a strategy to promote the social and emotional development of young people; however, research has not been conclusive as to the effects produced by it. The variability of the results seems to be due, on the one hand, to the volubility of the compared programs and, on the other hand, to the singularity of the tutoring relations, influenced by personal variables, by the context of the relation or the duration of the same. The positive results, according to several studies cited by Alarcão and Simões [11], refer to the development and reinforcement of communicational and social skills, attachment to peers and adults, reduction of disruptive behaviors in the classroom and reduction on the number of school disciplinary reports. At the instrumental level, there seems to exist improvements in the school results and in the effort put in the academic work $[14,18]$.

At the school under study, some of the generalist teachers are also tutors, investing much of their time in interacting with the student, his/her family, and specialists in out-of-school support services. One tries to understand the multifaceted knowledge of the student, through a systemic and strong relationship, promotes an action capable of guiding him/her to the accomplishment of a personal life project, helping him/her to discover a meaning for learning and stimulating him/her to enjoy knowledge. Ultimately, one intends to contribute to the improvement of the academic skills of the student, positively influencing 
his/her attitude towards school and learning, in a search of achievement of his/her academic and personal potential.

The tutor is positioned in a privileged situation by offering a more informal relational context, centered on the student's identity development work, with academic objectives to be achieved as a consequence of an individual and group intervention in person, in the individual and in his/her individuality. It is thought that the role of the tutor may be decisive in mobilizing the student for an effective investment in his or her school performance. This position seems really favored since, moving in various networks of the tutoring life, it has the possibility to accumulate a deeper knowledge about the same, being able to work more effectively on his/her beliefs of self-esteem, selfconcept and self-efficacy. Increasing these beliefs seems essential, since students appear to be more easily involved in learning situations when they consider that their skills, abilities and talents will be highlighted [14], presenting self-concept and selfefficacy as essential variables in mediating school performance [21,22].

In our perspective, this understanding of motivation as a mediated process by cognitive and affective variables constitutes a great advance in the educational field, allowing us to embark on ignored or neglected areas, emphasizing the quality of the pedagogical relation and the broad role that the teacher's image, in general, and the tutor, in particular, can play in the student's mobilization for his/her full achievement.

\section{Alternative Program Classes - Programa Oportunidade I}

It is intended for students between the ages of 11 and 18 who show a history of recurring failure. It aims to improve the student's socialization and integration in the community; it contributes to the reduction of social exclusion factors; it prevents early school drop-outs and it answers to repeated school failure up to the $9^{\text {th }}$ grade. It also complies with the assumption that the age level of the students should be taken into consideration, as well as their profile of competence in the constitution of the classes, which should not exceed eighteen elements.

With these classes, a rapid and effective recovery of schooling is attempted, with no notion of school year, neither passing nor flunking. The evaluation is predominantly formative, allowing the adjustment of teaching and learning processes and strategies. Whenever needed, students may enroll in a regular curriculum class, enrolling in the school year recommended by his/her teachers, after considering their age and performance profile.

\section{Discussion}

The results obtained align, in general, with the findings of recent studies in this area, however, given the specificity of the context and of the studied population, it was possible to detect some deviations.

To test the sub-hypotheses, it was used as a decision criteria, to accept or reject the null hypothesis, a significance level $(\alpha) \leq 0,05$. However, if there were significant differences for a significance level $(\alpha) \leq 0,10$ these would be duly commented. The sub-hypothesis no. 1.1 was tested with the Student $t$ test for a sample and the sub-hypothesis no. 1.2 was analyzed with Pearson's correlation coefficient. The sub-hypotheses no. 1.3 and 2.1 were analyzed with the Student $t$ test for independent samples. The assumptions of these tests, of normal distribution and homogeneity of variances, were analyzed with Kolmogorov-Smirnov and Levene's tests. In cases where these assumptions were not satisfied, they were replaced with the Student $t$ test for paired samples using Wilcoxon's test and the Student $t$ test for independent samples using Mann-Whitney's test. It was accepted the normal distribution in the samples with the size greater than 30 , according to the central limit theorem. To test the sub-hypotheses 1.4 and 1.5, the Student $t$ test was used for paired samples.

The statistical analysis was made with SPSS (Statistical Package for the Social Sciences).

After a careful analysis of the results, it was proven that the students enrolled in the educational recovery programs show extremely low motivation levels $\mathrm{t}(71)=-13.04, \quad \mathrm{p}=0.000$, revealing also unsatisfactory school results (an average of $41.18 \%$ ). It is shown, in these two variables, a parallelism with the international researches [9], [11], [12] and [14] which proved a positive, significant and reciprocal correlation between the motivation and the school results and show that students with school failure demonstrate a set of inhibitory motivation beliefs towards learning, being school failure an obstacle to enjoy learning.

It was found that the boys have significantly higher demotivation levels than the girls, meeting the results of studies carried out by Santos and Zenorini [15] where it was assessed that girls tend to be less unmotivated and more orientated to the learning goals than boys that are more oriented to the Performance goals. Finoto [16] and Seabra [17] consider that the motivation discrepancy among sexes seems to be related to the fact that girls are culturally seen as more obedient and hard-working, receiving more support from teachers, creating moments of conflict in the relationship between the teacher and male students, creating a more favorable classroom environment for the girls, influencing positively their motivation. In the case of the population being studied, it could be a constraint to 
the relationship between the student/(boy) and teacher the fact that this community, culturally, devalues the position of women in the society, triggering difficulties in establishing the authority and originating disruptive behaviors that influence motivation and learning.

The age variable was also studied during the assessment of the motivation levels of the students' before and after the application of the Motivation Program and it was concluded that, contrary to the reference literature and studies that reiterated a negative and significant relation between age and level of student motivation [12], in the studied population, it is not the case. The above studies were carried out in different contexts with different samples and none has looked into students integrated in school recovery programs, distancing them from the geographic, social and educational reality of the population covered by this investigation. The internalization of the irreversibility of failure may justify the significant demotivation levels in younger students, whereas the older students seem to feel more resigned to the fact that they did not attend a regular school program, identifying themselves with a more functional work. The high demotivation levels presented before the application of the Motivation Program leave, however, little room so that one can check a representative oscillation related with age. However, it was possible to detect an approach to the above referenced studies where the only seven students who showed to be motivated in EMAPRE A fit in the lower age group of the studied population.

Analyzing in particular the seven students in question, it can be detected that their positive motivation levels are always associated with the result above the average in the Pre-test $(64.4 \%$ vs $41.18 \%$ ). There are some similarities between these seven students, being the most significant found in the family relationship with the student and the school, perceiving a strong partnership between the parents and the homeroom teacher, as well as a dynamic monitoring of the students' school life. This dedication is reflected in monitoring the homework assignments, in showing up at the parent teacher interviews; in participating in the activities developed in the classroom context, in attending sports and artistic activities, in showing affection and personal availability, factors considered [18] decisive for the motivation and academic success. It was found that these seven students came from households with low income, however, in the seven families, the father was employed, four of which also received Social Assistance Benefits. These households' size were below the average of the studied population, showing an average of 2.2 siblings compared to the overall average of 3.5 siblings. According to a study by Vasconcellos [19], low family income has a negative effect on student motivation, without the possibility to invest in materials capable of stimulating interest and curiosity.

It was analyzed the level of education of the seven mothers, given that Portugal is one of the OECD countries where the intergenerational transfer is particularly distinct. It was found that the level of education is the 6th grade, in contrast to the remaining studied population in which $24.2 \%$ is illiterate and $84.2 \%$ finished the 4th grade. These results align with Machado and Gonzaga's [20] where it was shown that more educated mothers tend to show more positive expectations regarding the educational future of their children, having a notable influence on their self-efficacy beliefs and that better educated households have more access to culture and information, making them potentially more capable of transmitting knowledge and to develop skills and curiosity in their children. The analysis was confined to the mothers in the sense that Leal found that the school influence is statistically significant only in their case. According to Gentile [21], the fact that there is the above monitoring does not guarantee success in school, however, it may be decisive with the combination of other variables such as personal taste for the subject and integration in a mentoring program. The seven students who proved to be motivated in EMAPRE A indicated that Portuguese is their favorite subject and six of them were involved in a mentoring project. When implementing EMAPRE A, it was found that the students who benefitted from mentoring showed lower demotivation levels than the rest $(-8.643$ vs. -4.02$)$, aligning with Alarcão e Simões [11] that quote studies that conclude that mentoring has a positive effect on motivation and student learning. For these results, it may have contributed the fact that the mentor teacher, by moving around in the various networks of life of the mentored, in a closer context, has assumed a key role in motivating and mobilizing students for learning.

Afterwards, the results of EMAPRE A and EMAPRE B were compared and it was noticed that all students increased statistically and in a significant way their motivational levels following the implementation of the Motivation Program (-13.04 vs. 15.94), showing positive results academically and a significant relation with this tendency, aligning with the conclusions of the studies carried out by Lourenço and Paiva [14], Martinelli and Genari [13] and Sergio [12]. The students assessed the Motivation Program in 2.7 out of 3 points and all of them said that they would like to continue to benefit from this intervention strategy. The issues that had greater unanimity were related to the affective and relational nature of the program, with increased sense of well-being and belonging, with the rise of beliefs of self-efficacy and the development of selfconcept and self-esteem, in a dynamic of 
participation, discovery and significance, in a clear recognition of the importance of the pedagogical relationship quality for motivation and educational success. $85.9 \%$ of the students indicated that motivation was the most decisive key variable for learning, followed by the teachers $(77.5 \%)$ and personal effort $(67.6 \%)$, mentioning that the three most crucial factors in order to feel motivated to learn were To believe that I am capable (97.3\%), The teacher's help (64.8\%) and The teacher explains well $(60.6 \%)$, being that all the answers gave emphasis on the quality of the pedagogical interaction as a motivation promoter to learn. The teacher's sweetness $(88.7 \%)$, the teacher's understanding $(42.2 \%)$ and the quality and diversity of activities $(70.4 \%)$ were the most frequently variables mentioned by the students for the success of the Motivation Program and for the improvement of the school results, focusing again on the quality of the teacher's action and interaction. The emotional method that involved the whole delineation of the Motivation Program, as well as its results, align with the conclusions of Magalhães [22] and Paiva and Lourenço [14], who have assessed that the affective elements were decisive for the teacher to be able to motivate, encourage and support students in the discovery of new knowledge and skills. Although motivation influences positively and significantly the performance of students, it is not possible to establish between them a direct proportionality to the extent that, even motivation being as an enhancer factor of good educational results, it will be always conditioned by other variables to be considered in learning. However, only three students have shown an increase of motivation associated with a reduced performance. One was absent for two-thirds of the year, not allowing a concerted work at the level of the subject's skills. Another one, although he/she had high motivation level, reversed his/her progress when institutionalized.

The factors like the school devaluation, lack of school monitoring by parents; big households [17] and [19]; the high level of illiteracy [18]; situations of negligence in the primary care $(29.5 \%$ of the studied population is monitored by the Children Protective Services and/or by the Juvenile Court); some cognitive constraints $(38 \%$ of the students belonged to the Special Education System) and the difficulties felt by the teacher in working with social and personal realities so extreme can contribute to the understanding that the school results improve with the increase of motivation, but not to the same scale.

In conclusion, the Motivation Program had a very positive and significant effect on the less motivated students, being that among the fifteen mostly motivated at the end of the application of the Motivation Program, ten presented a motivational average of $-14,3$ points before the program, but also on individuals who did not show demotivation levels at the beginning, verifying that the seven students motivated in the EMAPRE A, continue to be among the most motivated on EMAPRE B. Triangulating the results of EMAPRE $B$, the results in the Posttest, the most significantly increase in motivation, as well as in the school results, it was concluded that, from the sixteen students for which this correlation was more significant, $50 \%$ belonged to the lower age groups of the studied population and the other $50 \%$ to the highest level, not verifying any impact on the age variable. It was not shown, in these sixteen cases, a predominance of the students covered by the mentoring program. It was found that thirteen students $(81.3 \%)$ belong to a family where the father has a paying job (confirming the effect of household income), that only four students $(25 \%)$ benefit from the parents' school support and four students (25\%) are being monitored by the Children Protective Services. Regarding the mothers' education, it can been seen that the majority of them $(69 \%)$ have no more than the fourth grade, $18.8 \%$ are illiterate and only $12.5 \%$ have qualifications above average. It was concluded, therefore, that the application of the Motivation Program minimized some family, economic, emotional and social differences with a significant impact on motivation and student learning.

$95.8 \%$ of the studied population improved over the year, being that $84.5 \%$ of the students managed to develop the skills of their curriculum. Twelve students $(16.9 \%)$ were automatically reinstated in the normal curriculum, following the existing programs, benefiting from minor adjustments in the formal stages of evaluation, without any harm in the development of structural skills of the curriculum.

\section{Conclusion}

Once again it was confirmed that the teaching and learning process is permeated by variables that sharpen the curiosity of researchers and fill the minds of educators, in a desire to outline intervention strategies that promote effective equality of opportunities in a school of masses.

It was seen, converging with the literature, that the motivation to learn seems strongly influenced and supported by teacher-student interaction, by its quality in an affective dimension of education in which each party has its space and its value, in a dynamic of discovery, participation and mutual support, working the beliefs of self-efficacy, raising self-concept and self-esteem and developing resilience in a demand sustained by success that in this study is effective.

Not being able to extrapolate the findings of this research to other realities and contexts, it can assess tendencies, supporting lines of action for this population. Thus, one may intervene in the 
effectiveness of educational recovery programs, establishing them as alternative paths of respect for individuality and fight school dropouts.

It is considered as a limitation of the study its nine month intervention period not allowing to assess the medium and long terms of the effect of motivation and of pedagogical relationship on the course and on the academic results of the students involved. It is suggested, therefore, to carry out a longitudinal study with this objective, covering other findings and expanding fields of view, aiming at equal opportunities and the effectiveness of public school.

\section{References}

[1] L. Correia, Dificuldades de Aprendizagem Específicas: Contributos para uma definição portuguesa, 2008.

[2] A. Clementino, Teorias de Ensino. Brasil, 2011.

[3] R. Cortez e M. Faria, Distúrbios de Aprendizagem e os Desafios da Educação Escolar. Revista Eletrónica Saberes da Educação, 2 (1), 2011.

[4] P. Gonçalves, Estratégias de Aprendizagem em Contexto Educativo e Formativo: Contributo para a Aprendizagem ao Longo da Vida, Universidade Fernando Pessoa, Porto, 2009.

[5] A. Pires, L. Cid, C. Borrego, J. Alves and C. Silva, "Validação Preliminar de um Questionário para Avaliar as Necessidades Psicológicas Básicas em Educação Física", Motricidade 6 (1), 2010, pp. 33-51.

[6] E. Leal, G. Miranda and C. Carmo, Motivação Sob a Perspetiva da Teoria da Autodeterminação: Um Estudo da Motivação de Alunos do Curso de Ciências Contáveis, Universidade Federal de Urbelândia, 2013.

[7] P. Cordeiro, Construção e Validação do Questionário de Motivação Escolar Para a População Portuguesa: Estudos Exploratórios, Universidade do Minho, Braga, (2010)

[8] M. Paulino, Auto-Regulação em Contexto Escolar: A perspectiva da Teoria da Autodeterminação, Universidade do Porto, Porto, 2009.

[9] M. Paiva and E. Burochovitch, "Orientações Motivacionais, Crenças e Desempenho Escolar dos Estudantes do Ensino Fundamental", Psicologia em Estudo, 15 (2), 2010.

[10] Instituto Nacional de Estatística, Censos 2011 Resultados definitivos: Região Autónoma dos Açores, 2012

[11] M. Alarcão e F. Simões, "O Lugar da Relação na Promoção do Sucesso Académico: Metodologia TUTAL, Tutoria Individual e Tutoria Grupal". Actas do VII Congresso de Inovação Educacional. Angra do Heroísmo, Universidade dos Açores. (2008)

[12] M. Sérgio, V. Monteiro, L. Mata and F. Peixoto,
"Motivação para a Língua Portuguesa: sua relação entre o género, o desempenho e o clima de sala de aula em alunos do $4^{\circ}$ ano", Atas do VII Simpósio Nacional de Investigação em Psicologia, Universidade do Minho, 2014.

[13] S. Martinelli and C. Genari, "Relações entre Desempenho Escolar e Orientações motivacionais", Estudos de Psicologia, 14 (1), 2009, pp. 13-21.

[14] A. Lourenço and M. Paiva, "A Motivação Escolar e o Processo de Aprendizagem", Ciências e Cognição, 15 (2), 2010, pp.132-141

[15] A. Santos, J. Mognon, T. Lima and N. Cunha, "A relação Entre a Vida Acadêmica e a Motivação para Aprender em Universitários", Revista Semestral da Associação Brasileira de Psicologia Escolar e Educacional, Brasil, 15(2), 2011, pp. 283-290.

[16] B. Finoto, K. Oliveira, T. Oliveira, N. Naves and K. Stagliano, Validação da Escala de Estratégias e Motivação para a Aprendizagem: Estudo Considerando o Género, Universidade Estadual de Londrina, 2011.

[17] T. Seabra, "Desigualdades Escolares e Desigualdades Sociais", Sociologia, Problemas e Práticas, 59, 2009, pp. 75-106.

[18] M. Souza, "Família/Escola: a Importância dessa Relação no Desempenho Escolar", Programa de Desenvolvimento Educacional, Paraná, 2009.

[19] L. Vasconcellos, "A Relação entre Frequência Escolar e Renda Familiar no Brasil", Pesquisa e Planejamento Económico, 35(2), 2005.

[20] D. Machado and G. Gonzaga, "O Impacto dos Fatores Familiares Sobre a Desfasagem Idade-Série de Crianças no Brasil", RBE, 61 (4), 2007, pp. 449-476.

[21] P. Gentile, "Parceiros na Aprendizagem", Nova Escola, 193, São Paulo, 2006

[22] S. Magalhães, "Relação Pedagógica, Afetividade, Sensibilidade: Pressupostos Transdisciplinares para a Formação Docente", Educação e Fronteiras On-Line, 1 (3), 2011, pp. 51-63. 